Proceedings

\title{
Optimization of Hydrocolloid Levels in Medium-Chain Triglyceride-Enriched Soymilk by Response Surface Methodology ${ }^{\dagger}$
}

\author{
Irene Tonette Y. Villones * and Benelyn D. Dumelod *
}

Citation: Villones, I.T.Y.;

Dumelod, B.D. Optimization of Hydrocolloid Levels in MediumChain Triglyceride-Enriched Soymilk by Response Surface Methodology. Proceedings 2021, 70, $\mathrm{x}$. https://doi.org/10.3390/foods_202007815

\section{Published: 10 November 2020}

Publisher's Note: MDPI stays neutral with regard to jurisdictional claims in published maps and institutional affiliations.

Copyright: $\odot 2020$ by the authors. Licensee MDPI, Basel, Switzerland. This article is an open access article distributed under the terms and conditions of the Creative Commons Attribution (CC BY) license (http://creativecommons.org/licenses/by/4.0/).
Department of Food Science and Nutrition, University of the Philippines Diliman, Quezon City 1101, Philippines

* Correspondence: iyvillones@up.edu.ph (I.T.Y.V.); bddumelod@up.edu.ph (B.D.D.)

+ Presented at the 1st International Electronic Conference on Food Science and Functional Foods, 10-25 November 2020; Available online: https://foods_2020.sciforum.net/.

\begin{abstract}
The application of medium-chain triglycerides (MCT) in food items can pave the way for its increased utilization and for consumers to avail of its benefits. Preliminary studies have indicated that soymilk enrichment with MCT requires the application of hydrocolloids. This study was conducted to determine the optimum levels of kappa-carrageenan (K), locust bean gum (L), and glycerine $(G)$ in MCT-enriched soymilk using response surface methodology (RSM). Addition of $30 \mathrm{~mL}$ MCT per $500 \mathrm{~mL}$ soymilk formulation was based on consumer acceptance test $(n=51)$. Ranges of input variables were $0.025-0.063 \%(w / v)$ for $\mathrm{K}$ and $\mathrm{L}$, and $1.0-2.0 \%(v / v)$ for G. Two-factor interaction (2FI), quadratic, and linear models which predicted the overall acceptability (OA), emulsion stability (ES), and product cost $(\mathrm{PC})$, respectively, were generated: $\mathrm{OA}=6.19-0.10 \mathrm{~K}-0.07 \mathrm{~L}-0.17 \mathrm{G}+$ $0.02 \mathrm{KL}+0.21 \mathrm{KG}-0.33 \mathrm{LG} ; \mathrm{ES}=9.24+0.32 \mathrm{~K}+0.08 \mathrm{~L}-0.01 \mathrm{G}+0.34 \mathrm{KL}-0.21 \mathrm{KG}+0.61 \mathrm{LG}-0.08 \mathrm{~K}^{2}+$ $0.16 \mathrm{~L}^{2}+0.16 \mathrm{G}^{2} ; \mathrm{PC}=299.62+0.37 \mathrm{~A}+0.40 \mathrm{~B}+0.67 \mathrm{C}$. A hydrocolloid combination with $0.025 \% \mathrm{~K}$, $0.025 \% \mathrm{~L}$, and $1.0 \% \mathrm{G}$ was predicted and selected as the "optimal" solution ( $\left.\mathrm{d}_{\mathrm{i}}=0.903\right)$. Model validation using the optimal and two suboptimal $(0.059 \%$ and $0.062 \% \mathrm{~K}, 0.033 \%$ and $0.043 \% \mathrm{~L}$, and $1.00 \% \mathrm{G})$ settings showed that the actual responses to both optimal (7.35 OA, $9.90 \mathrm{~mL}$ ES, and Php 292 PC) and sub-optimal solutions (6.80 and 5.98 OA, $10 \mathrm{~mL}$ ES, Php 293 PC) were within the 99\% $(\alpha=0.01)$ confidence and prediction intervals of the model.
\end{abstract}

Keywords: kappa-carrageenan; locust bean gum; medium-chain triglycerides; response surface methodology; glycerine; soymilk

\section{Introduction}

Triglycerides are formed from the esterification of one molecule of glycerol with three molecules of fatty acids and may be classified based on the chain length of attached fatty acids [1]. The majority of dietary fats and oils are widely composed of long-chain fatty acids (LCFA). LCFA, however, usually induce negative effects on glucose and insulin balance, as well as in body weight and adipose tissue mass gain [2,3]. In relation to this, the need for an alternative fat as energy source in the form of medium-chain triglycerides (MCT) derived from medium-chain fatty acids (MCFA) has long been recognized $[4,5]$.

MCT are primarily fractionated from coconut oil thus its incorporation, as well as coconut oil, into a variety of foods and beverages can be a promising approach towards their efficient utilization [6,7]. Soymilk is a popular traditional drink among Asian countries which, aside from being able to address problems related to milk protein allergy and lactose intolerance, also has nutritional qualities comparable to that of dairy milk [8-11]. 
This was chosen as an alternative medium since most MCT-based products are milk-based $[5,12,13]$.

Emulsifiers and stabilizers enhance emulsion stability by producing consistent texture and preventing coalescence or the separation of the two phases [14-16]. Their main function is to act as a steric stabilizing agent that provides complete surface coverage and strong adsorption to protect the dispersed molecules from aggregating during processing and storage $[17,18]$.

Developing a consumer-acceptable, stable, and cost-competitive MCT-enriched soymilk emulsion with the optimum levels of emulsifier and stabilizers can help address the need for novel applications of both coconut oil and soymilk in the country. MCT-enriched soymilk can also be considered as a functional food.

\section{Materials and Methods}

\subsection{Raw Materials}

MCT oil (Laurin, ChemRez Technologies, Philippines) was obtained from various local stores in Quezon City. Soymilk (Banawe Soybean Curd Food Products Corporation, Philippines) was bought at Php 55.00 per $500 \mathrm{~mL}$ bottle. Glycerine (Peotraco Industries Incorporated, Philippines) in $100 \mathrm{~mL}$ containers produced from the same batch and locust bean gum and kappa ( $\kappa)$-carrageenan (Mega Polygums Corporation, Philippines) were bought from a local store and from Marcel Carrageenan, respectively, located in Quezon City, Philippines.

\subsection{Preliminary Study for the Development of MCT-Enriched Soymilk}

The preliminary study was based on formulation [19] with $30 \mathrm{~mL}$ of MCT oil per 500 $\mathrm{mL}$ soymilk. Glycerine at $0.2 \%(v / v)$ was added and mixtures were vigorously stirred for one min. To test the stabilizing capacity, $0.03 \%(w / v)$ each of $\kappa$-carrageenan and LBG, and $0.025 \%(w / v) \kappa$-carrageenan-LBG (50\% carrageenan: 50\% LBG) combination were weighed in 50-mL beakers. Soymilk mixtures at $50 \mathrm{~mL}$ were dispensed into the labeled beakers (plain soymilk-MCT mixture as control), homogenized using a blender (Oster) for $10 \mathrm{~s}$, and dispensed into duplicate 10-mL graduated cylinders. Phase separation between the soymilk and MCT oil was recorded at 5 min intervals for 90 min [20]. Samples were also observed for any visual and consistency changes.

\subsection{Experimental Design for the Determination of Optimal Concentrations of Glycerine, K-Car- rageenan, and Locust Bean Gum (LBG) in MCT-Enriched Soymilk}

Concentration ranges for the glycerine stabilizer, and the $\kappa$-carrageenan and LBG emulsifiers were based on suggested literature values [21,22] and used as independent variables $\mathrm{X}_{1}, \mathrm{X}_{2}$, and $\mathrm{X}_{3}$, respectively. A rotatable, central composite design (CCD) containing six replicate runs at the center point and 14 design points was used to determine the combination effects on three responses $\left(Y_{1}=\right.$ overall acceptability, $Y_{2}=$ emulsion stability, and $Y_{3}=$ cost) and were analyzed using Response Surface Methodology (RSM). Combinations generated were used in optimization (see supplementary material, Table S1).

Significance of each regression model (F-value) and the individual model coefficients ( $p$-value) at $\alpha=0.05$, as well as the comparison between the $\mathrm{R}^{2}$ and adjusted $\mathrm{R}^{2}$ were applied to fit data for each response to linear, interaction, and quadratic models. The generalized equation is given below where $Y$ is the predicted response; $\beta_{0}, \beta_{\mathrm{i}}, \beta_{\mathrm{ii}}$, and $\beta_{\mathrm{ij}}$ are the regression coefficients for intercept, linear, quadratic, and interaction terms, respectively, and $X_{i}$, and $X_{j}$ correspond to the independent variables.

$$
\mathrm{Y}=\beta_{0}+\sum \mathrm{ni}=1 \beta_{\mathrm{i}} \mathrm{X}_{\mathrm{i}}+\sum \mathrm{ni}=1 \beta_{\mathrm{ii}} \mathrm{X}_{\mathrm{i} 2}+\sum \sum \mathrm{ni}<\mathrm{j}-1 \beta_{\mathrm{ij}} \mathrm{X}_{\mathrm{i}} \mathrm{X}_{\mathrm{j}},
$$

Three-dimensional surface plots were generated for each response, showing the relationship between two independent variables with the third variable fixed at center level. Desirability scores $\left(\mathrm{d}_{\mathrm{i}}\right)$ were generated using Design-Expert version 11 (Stat-Ease Inc., 
Minnesota, USA) software based on the criteria presented in Table S2 (see Supplementary Material); $\mathrm{d}_{\mathrm{i}}>0.85$ from the predicted response values were reported in the optimal range for each input variable. Three combinations were considered for the verification processone "optimal" and two "suboptimal" (Supplementary Material Table S3). Model validation was done through Post Analysis. Response data were assessed for fitness using both 99\% two-sided confidence (CI) and prediction intervals (PI). Predictive capacity of the models was verified when actual mean data for each response variable was within the $\mathrm{CI}$ and PI values.

\subsection{Overall Acceptability Evaluation}

Fifty-one (51) untrained panelists evaluated the MCT-soymilk formulations. Samples were dispensed into 30-mL white, food grade, plastic cups labeled with three-digit random codes. These were served simultaneously and evaluated for overall acceptability through sensory evaluation using a 9-point hedonic scale $(1=$ dislike extremely; $2=$ dislike very much; $3=$ dislike moderately; $4=$ dislike slightly; $5=$ neither like nor dislike; $6=$ like slightly; $7=$ like moderately; $8=$ like very much; $9=$ like extremely). Data gathered were evaluated and expressed as means and standard deviations and analyzed using one-way analysis of variance (ANOVA) determined at 5\% significance level with SPSS Statistics version 22 Software (IBM Corporation, Armonk, New York, USA).

\subsection{Emulsion Stability Determination}

Fifty-mL portion of each formulation was placed in a $50-\mathrm{mL}$ beaker before dispensing into duplicate 10-mL graduated cylinders. Degree of emulsion stability was measured based on the volume of intact MCT-soymilk emulsion below the separated oil, if any. Phase separation was recorded for $90 \mathrm{~min}$ at 5-min intervals. Changes in appearance and consistency of the samples were also recorded.

\subsection{Product Cost Calculation}

Product cost (PC) for each run, presented in the formula below, was calculated by adding the individual prices of raw materials, depending on the amount used, as well as the packaging material.

$$
P C=(n \times P M)+S M+M+K+L+G,
$$

where $\mathrm{n}$ is the number of glass bottles used; $\mathrm{PM}$ is the price of the packaging material; $\mathrm{SM}$ is the price of soymilk; and $\mathrm{M}, \mathrm{K}, \mathrm{L}$, and $\mathrm{G}$, are the corresponding prices of MCT, $\kappa$-carrageenan, LBG, and glycerine, respectively.

\section{Results and Discussion}

3.1. Fitting of Models for the Determination of Optimal Concentrations of Glycerine, K-Carrageenan, and Locust Bean Gum (LBG) in MCT-Enriched Soymilk

\subsubsection{Effect of Hydrocolloid Concentrations on Overall Acceptability}

Incorporation of hydrocolloids resulted in overall acceptability mean scores ranging from 4.78 to 7.02 (Table S1). Based on the adjusted $\mathrm{R}^{2}$ value generated, the two-factor interaction (2FI) model was selected.

$$
\mathrm{OA}=6.19-0.10 \mathrm{~K}-0.07 \mathrm{~L}-0.17 \mathrm{G}+0.02 \mathrm{KL}+0.21 \mathrm{KG}-0.33 \mathrm{LG},
$$

Figure 1 shows the three-dimensional plots with slightly curved projections suggesting interactions among the independent variables. 


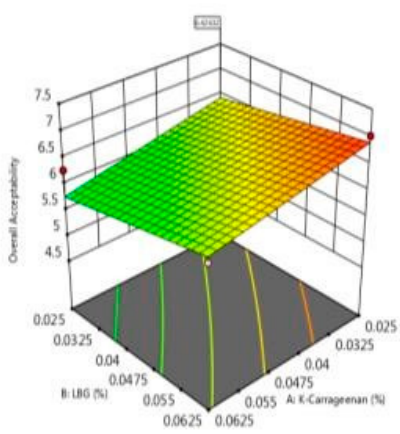

(a)

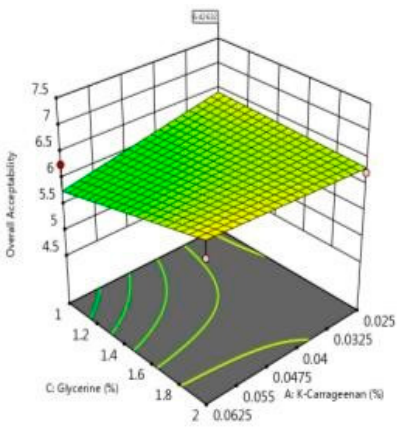

(b)

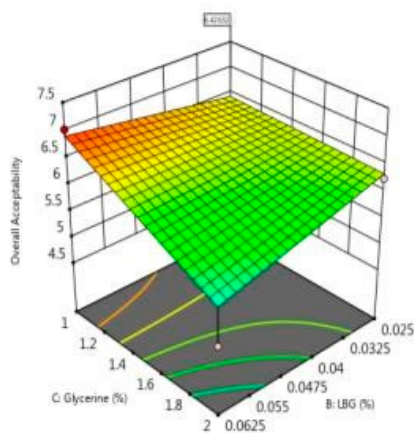

(c)

Figure 1. Response surface plots for overall acceptability of MCT-enriched soymilk as affected by varying concentrations of $\kappa$-carrageenan $(\mathrm{K})$, LBG $(\mathrm{L})$, and glycerine $(\mathrm{G})$.

ANOVA showed that the variables did not affect OA significantly ( $p>0.05)$, but plots presented a general trend - as the amount of LBG increases, with decreasing concentrations of $\kappa$-carrageenan (a) and glycerine (c), the overall acceptability of the soymilk also increases. Higher LBG concentrations correspond to higher overall acceptability as shown by the red surfaces of plots (a) and (c). However, it was apparent that the highest overall acceptability was recorded on the plot where LBG and $\kappa$-carrageenan (a) interactions were observed.

The positive effect of $\kappa$-carrageenan-LBG can be attributed to their synergism. K-carrageenan is widely used in stabilizing milk products because of its surface reactive sites in the presence of casein that inhibit phase separation [23,24]. In soymilk, glycinin is present instead of casein. However, glycinin, although different in terms of amino-acid chain, has the same isoelectric $\mathrm{pH}$ as casein at 4.6 [25]. The identical isoelectric $\mathrm{pH}$ of the two proteins could be the reason for similar behaviors when interacting with carrageenan.

\subsubsection{Effect of Hydrocolloid Concentrations on Emulsion Stability}

Incorporation of hydrocolloids resulted in emulsion stability data ranging from 6.5 to $10.0 \mathrm{~mL}$, generating a quadratic model expressed below. Figure 2 shows the three-dimensional plots of the effects of $\kappa$-carrageenan, LBG, and glycerine concentrations on emulsion stability.

$$
\mathrm{ES}=9.24+0.32 \mathrm{~K}+0.08 \mathrm{~L}-0.01 \mathrm{G}+0.34 \mathrm{KL}-0.21 \mathrm{KG}+0.61 \mathrm{LG}-0.08 \mathrm{~K}^{2}+0.16 \mathrm{~L}^{2}+0.16 \mathrm{G}^{2} \text {, }
$$

ANOVA suggested that the input variables did not significantly affect emulsion stability $(p>0.05)$. Plots generated showed lower separation (higher amount of intact soymilk) at higher concentrations of $\kappa$-carrageenan with lower glycerine and LBG concentrations. Interaction of glycerine and LBG (c) however, generated a saddle plot suggesting that the emulsion was also stable at either low or high concentrations.

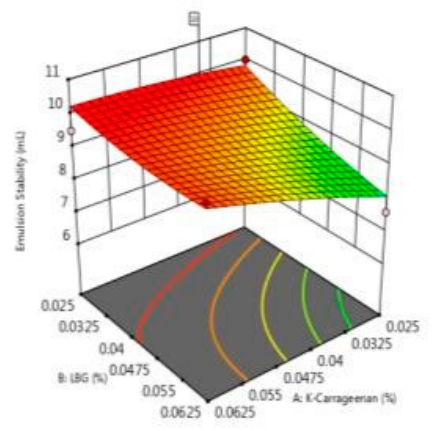

(a)

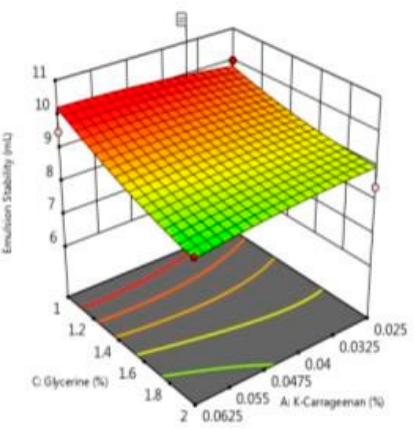

(b)

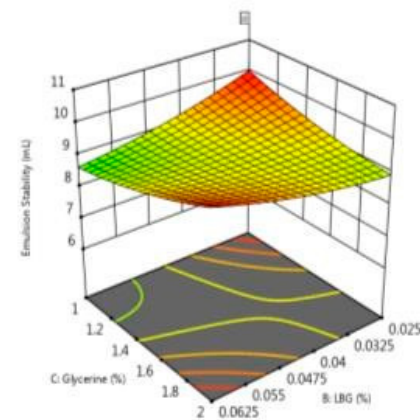

(c)

Figure 2. Response surface plots for emulsion stability of MCT-enriched soymilk as affected by varying concentrations of $\kappa$-carrageenan $(K)$, LBG $(L)$, and glycerine $(G)$. 
Interaction between $\kappa$-carrageenan and LBG (a) and between $\kappa$-carrageenan and glycerine (b), suggests that the effect of $\kappa$-carrageenan on emulsion stability was more apparent compared to individual effects of LBG and glycerine. Plots with $\kappa$-carrageenan showed pronounced curved surfaces compared to the plot with LBG and glycerine interaction (c). The low separation may be due to the observed curdling in some samples. Addition of $\kappa$-carrageenan in milk at concentrations higher than the ideal range causes the emulsion to gel rather than stabilize [26]. Because of its synergistic effect, LBG also increases gel strength of the emulsion, consequently increasing the viscosity $[27,28]$ and forming a curd-like consistency. A disadvantage of visual observation for separation monitoring, however, is the inability to determine phase boundaries when emulsions are opaque [29].

\subsubsection{Effect of Hydrocolloid Concentrations on Product Costs}

Figure 3 shows the plots between product cost, and the variables $\kappa$-carrageenan, LBG, and glycerine concentrations. All plots showed planar surfaces; positive slopes were observed in response surfaces with the glycerine concentration variable (b and c). Calculation of product cost per run was based on the percentage of the ingredient used, thus the flat surface generated from the interaction of LBG and $\kappa$-carrageenan (a) can be attributed to the minimal amount used in the formulation.

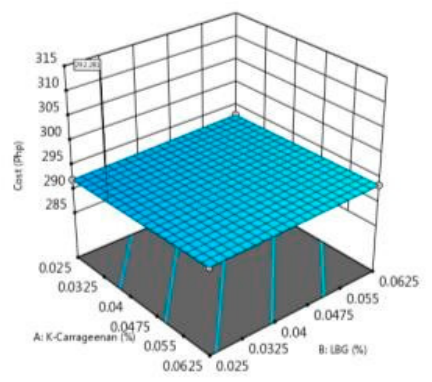

(a)

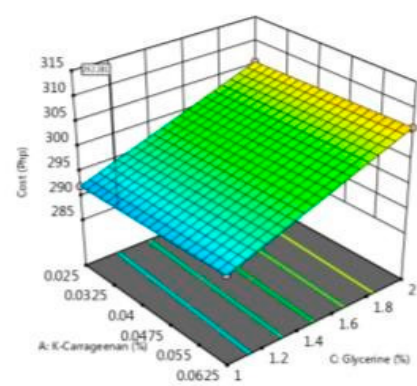

(b)

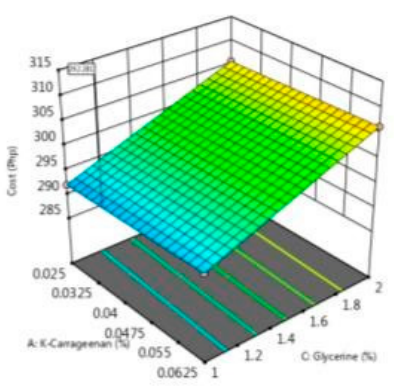

(c)

Figure 3. Response surface plots for product cost of MCT-enriched soymilk as affected by varying concentrations of $\kappa$-carrageenan $(\mathrm{K})$, LBG $(\mathrm{L})$, and glycerine $(\mathrm{G})$.

Incorporation of hydrocolloids resulted in product costs ranging from Php 288.21 to Php 311.03 per $2 \mathrm{~L}$ product (four $500 \mathrm{~mL}$ bottles) which generated the linear model in Equation (5).

$$
\mathrm{PC}=299.62+0.37 \mathrm{~K}+0.40 \mathrm{~L}+0.67 \mathrm{G},
$$

3.2. Validation of the Models with the Optimal Concentrations of Glycerine, K-Carrageenan, and Locust Bean Gum (LBG) in MCT-Enriched Soymilk

Based on the generated desirability from the optimization runs, actual optimal response values from model validation were compared to the predicted values as summarized in Table 1.

Table 1. Predicted and actual values for overall acceptability, emulsion stability ${ }^{1}$, and product cost of optimal and sub-optimal MCT-enriched soymilk formulations with corresponding confidence and prediction intervals.

\begin{tabular}{ccccccc}
\hline Response & \multicolumn{2}{c}{ Optimal } & \multicolumn{3}{c}{ Confidence Interval } & Prediction Interval \\
\hline & Predicted & Actual & Low & High & Low & High \\
\hline Overall Acceptability & 6.39 & 7.35 & 5.17 & 7.68 & 4.75 & 8.10 \\
Emulsion Stability (mL) & 9.80 & 9.90 & 6.58 & 13.06 & 5.54 & 14.10 \\
Product Cost (Php) & 292.00 & 292.00 & 292.00 & 292.00 & 292.00 & 292.00 \\
\hline
\end{tabular}


${ }^{1}$ Results are presented as volume of intact MCT-soymilk emulsion at the bottom of the cylinder after having been allowed to stand undisturbed for $90 \mathrm{~min}$.

Validation results showed that all models were able to predict the actual response values for overall acceptability, emulsion stability, and product cost. Actual values obtained were within the limits of the two-sided 99\% $(\alpha=0.01)$ confidence $(\mathrm{CI})$ and prediction intervals (PI). CI is used to estimate the reliability of the model while PI is for quantifying the model accuracy [30].

\section{Conclusions}

An acceptable and stable medium chain triglyceride (MCT)-enriched soymilk was successfully developed through the determination of optimal concentrations of glycerine, $\kappa$-carrageenan, and LBG. Incorporation of the hydrocolloids improved not only the emulsion stability of the soymilk but also its overall consumer acceptability as compared to MCT-soymilk emulsion alone. With the use of response surface methodology (RSM), the study was able to successfully generate validated models for determining the optimal concentrations of glycerine, kcarrageenan, and LBG and adequately predict overall acceptability, emulsion stability, and product cost.

Supplementary Materials: The following are available online at https://www.mdpi.com/25043900/70/1/34/s1, Table S1: Software-generated actual concentrations (\%) of combinations of glycerine, $\kappa$-carrageenan, and LBG for the optimization of hydrocolloid levels in MCT-enriched soymilk with the corresponding data for overall acceptability, emulsion stability, and product cost, Table S2: Specifications of criteria for the optimization of independent and dependent variables in the development of acceptable and stable MCT-enriched soymilk, Table S3: Software-generated actual concentrations (\%) of combinations of glycerine, $\kappa$-carrageenan, and LBG generated for model validation of hydrocolloid levels in MCT-enriched soymilk.

Author Contributions: Methodology, formal analysis, investigation, and writing-original draft preparation, I.T.Y.V. Writing - review and editing and supervision, B.D.D. All authors have read and agreed to the published version of the manuscript.

Funding: This research received no external funding.

Conflicts of Interest: The authors declare no conflict of interest.

\section{References}

1. Lester, J. Nomenclature of Fatty Acids and their Classification; Presentation; Institute of Food Science and Nutrition, University of Sargodha: Sargodha, Pakistan, 2016.

2. Iowa State University. Cholesterol and Cholesterol Oxides on Coronary Heart Diseases. Master's Thesis, Iowa State University, Ames, Iowa, 2018.

3. Montgomery, M.K.; Osborne, B.; Brown, S.H.J.; Small, L.; Mitchell, T.W.; Cooney, G.J.; Turner, N. Contrasting metabolic effects of medium- vs. long-chain fatty acids in skeletal muscle. J. Lipid Res. 2013, 59, 1-38.

4. Bach, A.C.; Ingenbleek, Y.; Frey, A. The usefulness of dietary medium-chain triglycerides in body weight control: Fact or fancy? J. Lipid Res. 1996, 37, 708-726.

5. Marten, B.; Pfeuffer, M.; Schrezenmeir, J. Medium-chain triglycerides. Int. Dairy J. 2006, 16, $1374-1382$.

6. Babayan, V.K. Medium-chain triglycerides-Their composition, preparation, and application. J. Am. Chem. Soc. 1968, 45, 23-25.

7. Shah, N.D.; Limketkai, B.N. The use of medium-chain triglycerides in gastrointestinal disorders. Pract. Gastroenterol. 2017, 160, 20-28.

8. Abiodun, P. Use of soya-beans for the dietary prevention and management of malnutrition in Nigeria. Acta Paediatr. Scand. Suppl. 2008, 374, 175-182.

9. Chen, S. Preparation of Fluid Soymilk. Proceedings of the World Congress on Vegetable Protein Utilization in Human Foods and Animal Feedstuffs; Applewhite, T.H., Ed.; American Oil Chemists' Society: Champaign, IL, USA, 1989.

10. Jiang, S.; Cai, W.; Xu, B. Food quality improvement of soymilk made from short-time germinated soybeans. Foods 2013, 2, 198212.

11. Muredzi, P. Soybean, Nature, Processing, and Utilisation; Lambert Academic Publishing: Saarbrücken, Germany, 2013 ; p. 229. 
12. Fabe, J.; Goldstein, R.; Blondheim, O.; Stankiewicz, H.; Darwashi, A.; Bar-Maor, J.A.; Gorenstein, A.; Eidelman, A.I.; Freier, S. Absorption of MCT in infant stomach. J. Pediatr. Gastroenterol. Nutr. 1968, 7, 189-195.

13. Harkins, R.W.; Sarett, H.P. Medium-chain triglycerides. J. Am. Med. Assoc. 1968, 203, 272-274.

14. Dickinson, E. Hydrocolloids as emulsifiers and emulsion stabilizers. Food Hydrocoll. 2009, 23, 1473-1482.

15. Moonen, H.; Bas, H. Mono-and diglycerides. In Emulsifiers in Food Technology; Whitehurst, R.J., Ed.; Blackwell Publishing Ltd.: Oxford, UK, 2004; pp. 40-45.

16. Mikkonen, K.S.; Tenkanen, M.; Cooke, P.; Xu, C.; Rita, H.; Willfor, S.; Holmbom, B.; Hicks, K.B.; Yadav, M.P. Mannans as stabilizers in oil-in-water beverage emulsions. J. Food Sci. Technol. 2009, 42, 849-855.

17. Dickinson, E. Hydrocolloids acting as emulsifying agents-how do they do it? Food Hydrocoll. 2018, 78, 2-14.

18. Ozturk, B.; McClements, D.J. Progress in natural emulsifiers for utilization in food emulsions. Curr. Opin. Food Sci. 2016, 7, 1-6.

19. Reilly, R. Special formula preparations that can be prepared in the home. Dis. Mon. 2006, 17, 1-30.

20. McClements, D.J. Critical reviews of techniques and methodologies for characterization of emulsion stability. Crit. Rev. Food Sci. Nutr. 2007, 47, 611-649.

21. Corbion. Available online: https://www.corbion.com/food/emulsifiers (accessed on 1 April 2019).

22. Food and Agriculture Organization of the United Nations. Available online http://www.fao.org/tempref/codex/Meetings/CCNFSDU/ccnfsdu36/CRDS/CRD_33.pdf (accessed on 1 April 2019).

23. Spagnuolo, P.A.; Dagleish, D.G.; Goff, H.D.; Morris, E.R. Kappa-carrageenan interactions in systems containing casein micelles and polysaccharide stabilizers. Food Hydrocoll. 2005, 19, 371-377.

24. Lal, S.N.D.; O'Connor, C.; Eyres, L. Application of emulsifiers/stabilizers in dairy products of high rheology. Adv. Colloid Interface Sci. 2006, 123-126, 433-437.

25. Kampf, N.; Nussinovitch, A. Rheological characterization of k-carrageenan soy milk gels. Food Hydrocoll. 1997, 11, 261-269.

26. Vega, C.; Dalgleish, D.G.; Goff, H.D. Effect of k-carrageenan addition to dairy emulsions containing sodium caseinate and locust bean gum. Food Hydrocoll. 2004, 19, 187-195.

27. Barak, S.; Mudgil, D. Locust bean gum: processing properties and food applications-A review. Int. J. Biol. Macromol. 2014, 66, 74-80.

28. Camacho, M.M.; Martinez-Navarrete, N.; Chiralt, A. Rheological characterization of experimental dairy cream formulated with locust bean gum (LBG) and l-carrageenan combinations. Int. Dairy J. 2004, 15, 243-248.

29. Choi, S.J.; Won, J.W.; Park, K.M.; Chang, P.S. A new method for determining the emulsion stability index by backscattering light detection. J. Food Process Eng. 2014, 37, 229-236.

30. Kim, C.; Choi, K.K. Reliability-based design optimization using response surface method with prediction interval estimation. J. Mech. Des. 2008, 130, 12401-1-12401-12. 